\title{
Long-term administration of aspirin inhibits tumour formation and triggers anti-neoplastic molecular changes in a pre-clinical model of colon carcinogenesis
}

\author{
SOUAD BOUSSEROUEL ${ }^{1,2}$, FRANCINE GOSSE ${ }^{1,2}$, MOURAD BOUHADJAR ${ }^{2}$, \\ LUC SOLER $^{2}$, JACQUES MARESCAUX ${ }^{2}$ and FRANCIS RAUL ${ }^{1,2}$ \\ ${ }^{1}$ University of Strasbourg Unit EA 4438, Faculty of Medicine, Laboratory of Nutritional Cancer Prevention; \\ ${ }^{2}$ Institut de Recherche contre les Cancers de l'Appareil Digestif (IRCAD), F-67000 Strasbourg, France
}

Received September 21, 2009; Accepted October 30, 2009

\section{DOI: 10.3892/or_00000663}

\begin{abstract}
Despite numerous studies aimed at verifying the anti-tumour activity of aspirin on colon carcinogenesis little is known on the molecular targets involved in the anticarcinogenic properties of this drug. We investigated the long-term administration of low dose of aspirin in a model of experimental colon carcinogenesis in rats. Adult Wistar rats received an intraperitoneal injection of azoxymethane (AOM) once a week for two weeks in order to initiate colon carcinogenesis. One week after AOM injection, rats received daily $0.01 \%$ aspirin $(6 \mathrm{mg} / \mathrm{kg}$ body weight) in drinking water for 10 months. Compared to AOM control rats, aspirin treatment for 10 months caused a $50 \%$ reduction of the number of aberrant crypt foci associated with a $50 \%$ reduction of prostaglandin E2 (PGE2) concentration and suppressed by $80 \%$ tumour formation in the colon. RT-PCR quantitative analysis showed that aspirin treatment reduced significantly $(\mathrm{P}<0.01)$ the AOM-triggered increase in mRNA levels of soluble inflammatory mediators (TNF $\alpha$ and IL-1ß) and metalloproteinases (MMP3 and MMP7). Conversely, we detected an increased expression level of $\alpha$-defensin-5 (Rd-5, 2 fold) and lipocalin-2 (LCN2, 4 fold), two markers of the innate immunity system. The expression of apoptosis-related genes such as death receptors and their ligands were reduced by aspirin and the $\mathrm{Bcl}-2 / \mathrm{Bax}$ transcript ratio droped, $\mathrm{Bcl}-2$ expression being reduced to the level found in saline control rats. The present study identifies new molecular targets triggered by aspirin in the colonic mucosa and may support the use of non-toxic low dose of aspirin in long-term treatments as a prophylactic approach against colon carcinogenesis.
\end{abstract}

Correspondence to: Dr Francis Raul, Laboratory of Nutritional Cancer Prevention, IRCAD, 1, Place de l'Hôpital, 67091 StrasbourgCedex, France

E-mail: francis.raul@ircad.u-strasbg.fr

Key words: colorectal cancer, chemoprevention, aberrant crypt foci, prostaglandin E2, gene expression

\section{Introduction}

There are basically two strategies for the prevention of colorectal cancer (CRC): early diagnosis of the disease and chemoprevention. Treatment of pre-malignant or early stage malignant lesions decreases the incidence and mortality of CRC (1-3). In recent years, the non-steroidal anti-inflammatory drugs (NSAIDs) have attracted a great interest as potential candidates for colorectal cancer chemoprevention. There is now a great body of evidence supporting the role of NSAIDs, particularly of aspirin, in tumour chemoprevention through their anti-inflammatory properties. Especially by targeting the cyclooxygenase 2 (COX-2) enzyme linked to inflammation and tumour growth through its effects on cell survival and angiogenesis $(4,5)$. Although the epidemiologic data in humans and the experimental data in rodents are generally consistent and show a strong relationship between aspirin use and the reduction of colorectal cancer incidence (6), they are not conclusive regarding the dose to be used, the duration of treatment and the route of administration (7-10). For example, aspirin has been shown to inhibit azoxymethane (AOM)induced colon cancer in rats when provided in the diet before colon cancer initiation and given throughout the study (9). It was also reported that aspirin prevented aberrant crypt foci (ACF) formation when administered 4 weeks after AOM injection (11). However, others have shown that similar concentrations of aspirin (200 and $400 \mathrm{mg} / \mathrm{kg}$ diet corresponding to a daily aspirin intake of $\sim 15-30 \mathrm{mg} / \mathrm{kg}$ body weight) did not prevent ACF formation in the colonic mucosa of AOM-treated rats (12). In the 1,2-dimethylhydrazine model of colon cancer, aspirin was effective in preventing colon tumours when administered during the initiation phase (before and during treatment with the chemical carcinogen); however, it was uneffective when aspirin was given after colon cancer initiation (4 weeks after carcinogen injection) (13). Other studies (14-18) have reported that treatment of normal rats with aspirin or indomethacin at doses that suppress prostaglandin production in the colonic mucosa, increased tritiated thymidine incorporation into mucosal DNA of colon, gastric fundus, small intestine and duodenum. This enhanced proliferative activity was associated with an increased risk of colon tumour formation $(19,20)$. Clearly, the influence of NSAIDs on colon 
carcinogenesis is complex and may be dependent on the nature of the NSAIDs, the doses used and/or the duration of the treatment. Furthermore, the molecular mechanisms and targets involved in the chemopreventive activity of NSAIDS are not yet clearly identified.

A systematic review of colon chemoprevention in rodents and humans has shown that the chemical carcinogen-induced rat model represents a good predictor of chemopreventive efficacy in humans (21). In this model, ACF are considered as putative pre-neoplastic lesions and ACF can be used as biomarkers to assess the efficacy of potential chemopreventive agents (22). Some of these lesions are precursors of adenomatous polyps and colorectal adenomas in rats and humans (23).

The goal of the present study was to determine whether the long-term treatment of rats with aspirin at a low dose $(6 \mathrm{mg} /$ $\mathrm{kg}$ body weight corresponding to a daily intake of $36 \mathrm{mg} / \mathrm{m}^{2}$ in humans) given in the drinking fluid after colon cancer initiation by AOM is able to prevent ACF and colon tumour formations. Treatment with aspirin was started one week after AOM injection and was continued for 10 months. In order to get more insight into the molecular targets involved in the anti-neoplastic effects of low dose of aspirin the expression of several key genes involved in the inflammatory, immune and apoptotic responses were measured in the colonic mucosa.

\section{Materials and methods}

Animals and treatments. All animal experiments were performed in accordance with the institutional guidelines of the French Ethics Committee (authorization n: 67-49, French Ministry of Agriculture). Male Wistar rats (5 weeks old) obtained from Charles River Laboratories (Les Oncins, France) and weighing 240-250 g were housed under standardized conditions $\left(22^{\circ} \mathrm{C}, 60 \%\right.$ relative humidity, $12 \mathrm{~h} \mathrm{light} / 12 \mathrm{~h}$ dark cycle, 20 air changes/h) and fed a standard diet with free access to drinking water. One group of rats $(n=12)$ received intra-peritoneal injections of azoxymethane (AOM) (SigmaAldrich, Saint Quentin Fallavier, France), $15 \mathrm{mg} / \mathrm{kg}$ body weight, once a week for 2 weeks. One week after the last injection of AOM, rats were randomly separated into aspirintreated $(n=6)$ and AOM control $(n=6)$ groups. The aspirintreated group received daily at $5 \mathrm{pm}$ a freshly prepared mixture of $0.01 \%$ aspirin (DL-lysine acetylsalicylate, SanofiSynthelabo, Paris, France) in drinking water. The daily intake of aspirin per rat was $(6 \mathrm{mg} / \mathrm{kg}$ body weight $)$. The AOM control group received drinking water. One group of rats $(n=6)$ injected with the excipient $(\mathrm{NaCl} 0.9 \%)$ was used as reference (saline rats) and kept under the same conditions. All rats consumed daily 30 to $34 \mathrm{ml}$ of the drinking fluid during the whole experimental period.

Assessment of aberrant crypts and tumours in the colon. All animals were sacrificed 10 months after the last AOM or saline injection. The entire colon was collected, washed with PBS buffer and cut out flat with the mucosa on the upper side in order to record the number, size and localization of tumours. The tumour sizes were evaluated at autopsy based on the formula $V=4 / 3 \pi \times(A / 2)^{2} \times B / 2$, where $A$ is the width of the tumour and $\mathrm{B}$ the length in millimeters. The determination of aberrant hyperproliferative crypts and ACF was performed on a 6-cm segment in length corresponding to the distal part of the colon. The segment was fixed in $10 \%$ buffered formalin and stained with $0.2 \%$ methylene blue for $5 \mathrm{~min}$, rinsed in Krebs-Ringer buffer, placed onto a glass slide and examined microscopically using a low power objective (x5) for the assessment of the number of hyperproliferative aberrant crypts and ACF. The histomorphological criteria for the identification of hyperproliferative aberrant crypts were i) an increased size, ii) a thicker epithelial cell lining and iii) an increased pericryptal zone relative to normal crypts.

Quantitative real-time reverse transcriptase-polymerase chain reaction analysis. RNA was isolated from mucosal scrapings of the mid colon. Total RNA was isolated by RNAeasy Plus Mini Kit (Qiagen, Austin, TX, USA). A high capacity cDNA reverse transcription kit (Applied Biosystems, Foster City, CA, USA) was used for cDNA synthesis as recommended by the supplier. PCR was performed by using ABI TaqMan gene expression assays for MMP7, MMP3 (assay ID: Rn00563467; Rn00591740), IL-1ß, TNFa (assay ID: Rn99999009; Rn99999017), and Bcl2, Bax, Rd-5, Fas (CD95), FasL, TRAIL, DR5, LCN2 (assay ID: RN99999125; RN02532082; RN01478512; RN00685720; RN00563754; RN00686175; RN01753393; RN00590612) according to the manufacturer's instructions. All samples were run in triplicate, in a $25 \mu 1$ reaction volume. Real-time RT-PCR was performed by using TaqMan Universal PCR master mix (Applied Biosystems) and Applied Biosystems Prism 7500 Sequence Detection System in triplicate wells. The data were analyzed by a comparative threshold cycle $\left(\mathrm{C}_{\mathrm{T}}\right)$ method. $\mathrm{C}_{\mathrm{T}}$ values were calculated using the 7500 SDS software (Applied Biosystems). Total RNA from colonic mucosa from the saline rats was used in all determinations as an external calibrator and the level of $\beta$-actin (assay ID: Rn00667869) mRNA in each sample was used as internal reference to normalize the data; mRNA relative fold changes were calculated using the $2^{\text {-DDCt }}$ method (24).

Determination of PGE2 concentration in colonic mucosa. A sample of the mucosal scraping was homogenized in 100 mmol/l Tris-HCl buffer, $\mathrm{pH} 7.8$, containing $1 \mathrm{mmol} / 1$ EDTA. After centrifugation at $10,000 \times \mathrm{g}$ for $15 \mathrm{~min}$ at $4^{\circ} \mathrm{C}$, the supernatants were collected for PGE2 measurements using the PGE2 assay kit (R\&D Systems Inc., Lille, France). The assay was performed according to the manufacturer's procedure.

Statistical analysis. Data are reported as mean \pm SE. Statistical differences between control and treated groups were evaluated using the Student's t-test. Differences between groups are considered significant at $\mathrm{P}<0.01$.

\section{Results}

Long-term low dose of aspirin inhibited promotion of colon carcinogenesis in AOM rats. Colon carcinogenesis was induced in rats by intra-peritoneal injections of the chemical carcinogen AOM once a week for 2 weeks. One week after the last injection rats received aspirin ( $6 \mathrm{mg} / \mathrm{kg}$ body weight) in their drinking fluid. After 10 months, the mucosal surface of 
the colon of rats receiving aspirin showed a significant reduction $(\mathrm{P}<0.01)$ in the number of pre-neoplastic lesions. The number of ACF and the total number of aberrant cypts were reduced by $50 \%$ in $\mathrm{AOM}$ rats receiving aspirin when compared with AOM control rats (Table I). No aberrant crypts or tumours were present in the colon of saline rats.

Striking differences were observed in the number and size of tumours present in the colon of AOM rats and aspirintreated AOM rats (Fig. 1). In the AOM rats, a total number of 21 tumours were recorded, in this group no rats were found tumour-free and 5 of 6 animals exhibited multiple tumours. Among these tumours, 5 had a size between 300 and $450 \mathrm{~mm}^{3}$, 5 between 50 and $300 \mathrm{~mm}^{3}$ and 11 tumours were $<50 \mathrm{~mm}^{3}$. In contrast, only 3 tumours were found in 3 of the 6 animals receiving aspirin, 2 small tumours not exceeding $15 \mathrm{~mm}^{3}$ and 1 tumour had a size of $50 \mathrm{~mm}^{3}$. No tumour was detected in the colon of saline rats.

Aspirin modulated the expression of inflammatory and hostdefence genes. IL-1B is an important pro-inflammatory cytokine, which together with tumour necrosis factor $(\mathrm{TNF} \alpha)$ are acting as primary initiators of the complex inflammatory response which is suspected to be positively associated with the formation of colorectal adenoma in humans (25).

In the colonic mucosa of AOM rats a significant $(\mathrm{P}<0.01)$ up-regulation of IL-1ß (12-fold) and TNF $\alpha$ (8-fold) were observed when compared with the saline-rats. The colonic mucosa of aspirin-treated AOM rats exhibited a significant $(\mathrm{P}<0.01)$ reduced expression of these inflammatory cytokines with a level close to that measured in the mucosa of saline rats (Fig. 2A).

In humans an increased expression of metalloprotease (MMP) genes has been associated to the early stages of cancer (26). We showed that the expression of MMP3 and MMP7 were significantly enhanced respectively by 8 - to 10 -fold in the colonic mucosa of AOM rats (Fig. 2A). Longterm treatment with aspirin maintained the gene expression of these MMPs near the level found in the mucosa of saline rats (Fig. 2A). We found also that two biomarkers of the innate immune system namely, $\alpha$-defensin (Rd-5) and lipocalin-2 (LCN2) were up-regulated (2- to 4-fold) in the colonic mucosa of aspirin-treated AOM rats compared to AOM rats and saline rats (Fig. 2A). This was consistent with the known negative correlation between the expression levels of host-defense genes and those implicated in the inflammatory response (27).

Aspirin is a non-selective inhibitor of COX activities leading to a lowering of prostaglandin (PG) concentrations in the colorectal mucosa. Accordingly, we found that long-term aspirin treatment was associated with a reduction of $50 \%$ of $\mathrm{PGE}_{2}$ concentration in the colonic mucosa when compared to AOM rats (Fig. 2B).

Aspirin modulated the expression of apoptotic genes. The ability of aspirin to prevent AOM-induced ACF and tumour formation may be correlated to regulatory effects on genes implicated in the control of cell survival and/or cell death. We measured the effects of aspirin treatment on the expression of genes involved in the control of two main cell death pathways: the extrinsic apoptotic pathway triggered by specific death
Table I. Effect of low dose of aspirin on preneoplasic lesions in distal colon.

\begin{tabular}{lcr}
\hline & Total AC/cm & ACF/cm \\
\hline Control (6) & $68.4 \pm 5.0$ & $21.0 \pm 1.6$ \\
Aspirin (6) & $30.3 \pm 3.1^{\mathrm{a}}$ & $9.8 \pm 0.7^{\mathrm{a}}$ \\
\hline
\end{tabular}

Total number of aberrant crypts (AC) and number of aberrant crypt foci $(\mathrm{ACF})$ per $\mathrm{cm}$ distal colon $(6 \mathrm{~cm}$ in length) in $\mathrm{AOM}$ rats and in rats receiving $0.01 \%$ aspirin in the drinking fluid. Values are the mean $\pm \mathrm{SE} .{ }^{*} \mathrm{P}<0.01$.

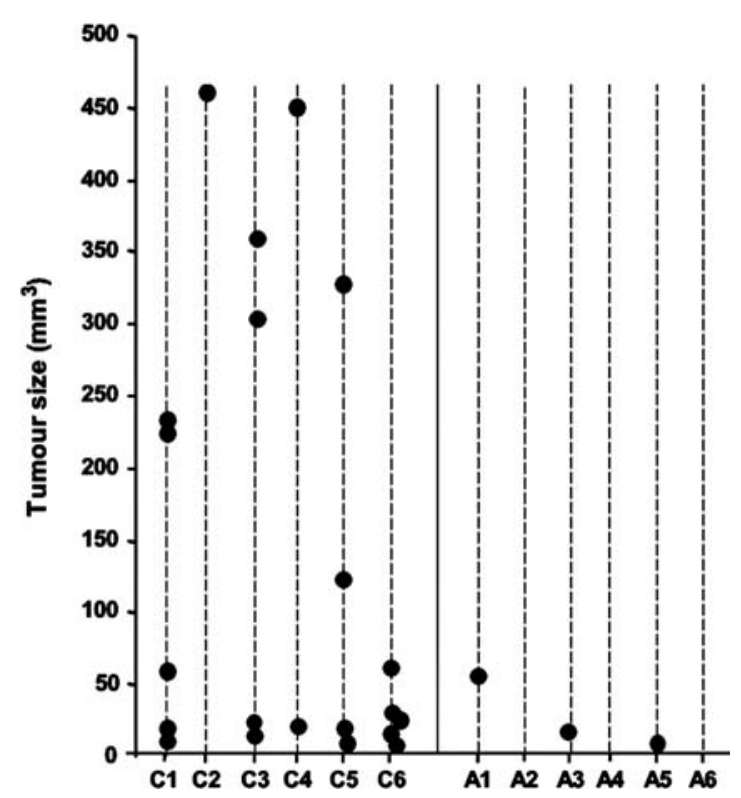

Figure 1. Number and size (in $\mathrm{mm}^{3}$ ) of tumours found at autopsy 10 months after AOM injection in each $\mathrm{AOM}$ control rat (C1 to $\mathrm{C} 6)$ and aspirin-treated $\mathrm{AOM}$ rat (A1 to A6).

receptors located at the cell surface Fas (CD95) or TRAIL receptors (DR5) and the intrinsic apoptotic pathway induced following mitochondrial injury. This intrinsic pathway is controlled by members of the Bcl-2 family, and more specifically by the anti-apoptotic Bcl-2 and the pro-apoptotic Bax proteins. Here, we show that the colonic mucosa of AOM rats exhibited an up-regulation of both pro-apoptotic (Fas, DR5, FasL, TRAIL, Bax, p53) and anti-apoptotic (Bcl-2) genes, with a major effect on Bcl-2 and DR5 which were respectively enhanced by 8 - and 12-fold when compared to saline rats (Fig. 3A and B). Aspirin treatment did not modify significantly the expression level of Bax and p53 in the mucosa of AOM rats. However, aspirin treatment caused a drastic downregulation of the Bcl-2 transcripts which were reduced to the level found in saline rats. The down-regulation of all apoptotic genes of the extrinsic pathway (Fas, DR5, TRAIL, FasL) was also observed in the mucosa of aspirin-treated AOM rats (Fig. 3B). Thus, these data suggested that long-term use of aspirin might reduce colonic pre-neoplastic lesions and other cellular events relevant to colon carcinogenesis through an 


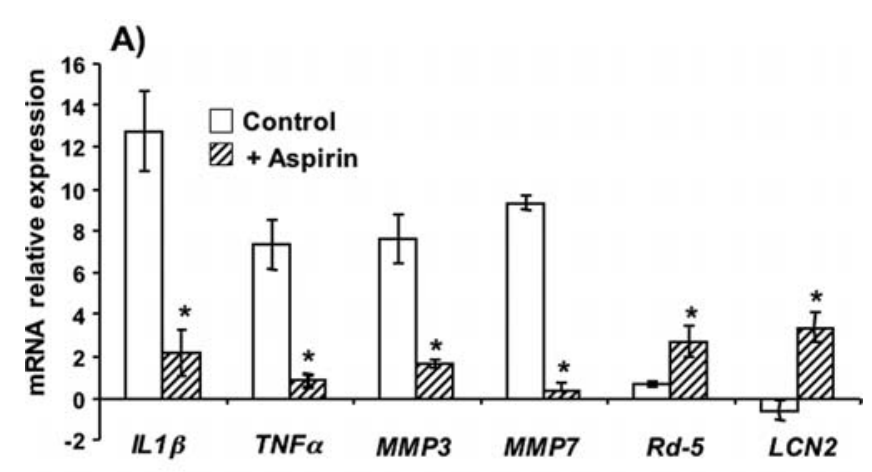

B)

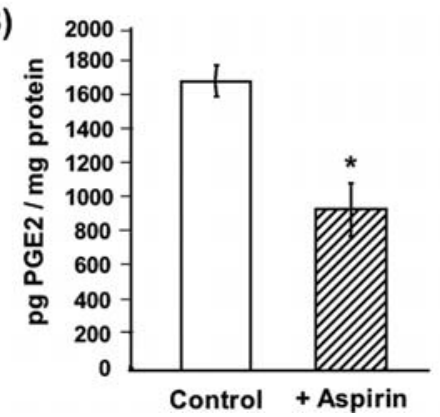

Figure 2. (A) Effect of low dose of aspirin on the genetic expression of pro-inflammatory cytokines, metalloproteases and biomarkers of the innate immunity system. The expression level of IL-1B, TNF $\alpha$, MMP7, MMP3, Rd-5 and LCN2 mRNA were measured by real-time RT-PCR in mucosal samples of the mid colon of AOM control rats and aspirin-treated AOM rats relative to the corresponding mRNA amount measured in saline rats used as reference (baseline); the amount of $B$-actin RNA measured in each sample was used to normalize the results. Data are mean $\pm \mathrm{SE}$ ( $\mathrm{n}=6$ rats/group). Inflammatory gene expression levels are expressed as mean $\pm \mathrm{SE} ; \mathrm{n}=6$ rats/group. Aspirintreated AOM rats vs. AOM control rats: ${ }^{*} \mathrm{P}<0.01$. (B) Effect of low dose of aspirin on mucosal PGE2 concentration in colonic samples of the mid colon. Values are means $\pm \mathrm{SE} ; \mathrm{n}=6$ rats/group. Aspirin-treated AOM rats vs. AOM control rats: ${ }^{*} \mathrm{P}<0.01$.

increased $\mathrm{Bax} / \mathrm{Bcl}-2$ transcript ratio favouring the intrinsic (mitochondrial) apoptotic pathway.

\section{Discussion}

The AOM-induced colon cancer rat model used in the present study is well established (21). In this model the induced tumours share many histopathological and genetical characteristics with sporadic colon tumours in humans. AOM initiates a mutistep carcinogenic process that transforms progressively the normal colonic epithelia into a carcinoma with pre-neoplastic lesions (aberrant hyperproliferative crypts) and adenomatous polyp as intermediate steps in the process (28). In humans, colon carcinogenesis is a long, chronic process that is thought to take up to 10 to 20 years (29). In the AOM-induced rat model, pre-neoplastic lesions (hyperproliferative aberrant crypts) appear 3 to 4 weeks after AOM injection and tumours are detected by 6 months, making this model very attractive for the screening of potential chemopreventive agents (30). As in the AOM-induced rat model, aberrant crypt foci (ACF) in humans represent an early preneoplastic step appearing before colorectal adenoma and are one of the earliest changes that can be seen in the colon of humans that may lead to cancer (31). The ACF/adenoma transition is favoured by the appearance of additional mutations and epigenetic alterations (32). During the process
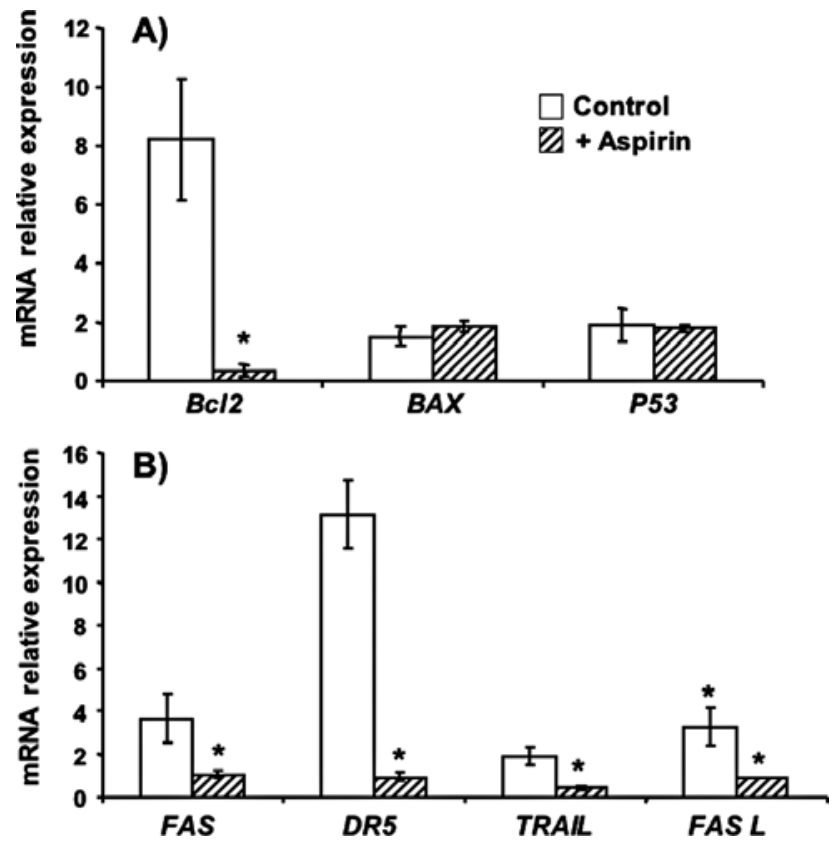

Figure 3. Effects of aspirin treatment on the expression of pro- and antiapoptotic genes. (A) Amount of Bc12, Bax and p53 mRNA and (B) amount of death receptors and ligand mRNA measured by real-time RT-PCR in mucosal samples of the mid-colon of AOM control rats and aspirin-treated AOM rats relative to the corresponding mRNA amount measured in saline rats used as reference (baseline); the amount of B-actin RNA measured in each sample was used to normalize the results. Data are mean \pm SE $(n=6$ rats/group). Apototic gene expression levels are expressed as mean $\pm \mathrm{SE}$; $\mathrm{n}=6$ rats/group. Aspirin-treated $\mathrm{AOM}$ rats vs. AOM control rats: ${ }^{*} \mathrm{P}<0.01$.

of carcinoma formation from normal colonic mucosa, precancerous cells release various growth factors and cytokines into their surroundings, recruit and re-program various other cell types to establish a 'tumour microenvironment' (33). There is now growing evidence that tumours are sustained and promoted by inflammatory signals from the surrounding microenvironment. Inflammation is implicated in all stages of carcinogenesis, i.e., initiation, promotion and progression $(34,35)$.

The non-steroidal anti-inflammatory drug aspirin has shown repeatedly anti-carcinogenic properties on colon carcinogenesis through its anti-inflammatory properties by inhibiting prostaglandin synthesis (6). However, due to increased risk of associated gastrointestinal toxicity the benefit of these drugs has to be weighed against the risk in long-term treatments. Therefore, in order to evaluate the anti-carcinogenic effects of long-term aspirin we used a very low dose of aspirin, corresponding to a 5- to 10-fold lower daily intake of aspirin reported in previous animal studies $(9-11,36)$ and corresponded in humans to a daily aspirin intake of $36 \mathrm{mg} / \mathrm{m}^{2}$. This dose used over the 10 months period showed no apparent toxicity. Both $\mathrm{AOM}$ rats and aspirin-treated rats exhibited similar body weight evolution reaching respectively $660 \pm 22 \mathrm{~g}$ and $642 \pm 28 \mathrm{~g}$ (mean value $\pm \mathrm{SD}$ ). In order to get more insight into the molecular targets involved in the anti-neoplastic effects of aspirin the expression of several key genes involved in the inflammatory, immune and apoptotic responses were measured in the colonic mucosa.

The present study showed that the long-term administration of aspirin given after colon cancer initiation suppressed 
AOM-induced colon tumorigenesis and reduced significantly ACF formation. The best known molecular target for aspirin is cyclooxygenase (COX). COX is a key regulatory enzyme involved in prostaglandin (PG) biosynthesis, which is strongly implicated in the induction of inflammation and cell proliferation (37). Inhibitors of the enzyme are associated with a reduction of up to $50 \%$ of colorectal cancer morbidity and mortality (38). Our data showed that the anti-carcinogenic effects of aspirin were associated with a $50 \%$ reduction in prostaglandin $\mathrm{PGE}_{2}$ concentration and to changes in the expression of key genes involved in the control of inflammatory, host defence and apoptotic responses.

It was recently reported in humans that $\mathrm{ACF}$ formation is closely related to tumorigenesis and that inflammatory genes of the MMP family such as MMP7 were activated during the early period of ACF formation (26). Several studies have reported on the major role of the MMPs in carcinogenesis transcriptional regulation (39). Here we showed that MMP3 and MMP7 expression were significantly enhanced in the colonic mucosa of AOM rats. The expression levels of these genes were significantly $(\mathrm{P}<0.01)$ lowered by aspirin treatment near the level found in the colonic mucosa of saline rats. Furthermore, we showed also that the AOM-induced overexpression of pro-inflammatory cytokine IL-1B and TNF- $\alpha$ were suppressed by aspirin treatment. Thus, we observed an inverse correlation between the genetic expression of the pro-inflammatory cytokines and the genetic expression of host-defence components of the innate immune system such as $\alpha$-defensin 5 (Rd-5) and lipocalin 2 (LCN2), these genes being up-regulated in aspirin-treated AOM rats. The functions of $\alpha$-defensin 5 and lipocalin 2 are currently thought to be not only involved in anti-microbial action, but also in the modulation of both the inflammatory and immune responses $(27,40)$ and these components are considered as active weapons against several cancer cell types $(41,42)$. Furthermore, the impaired expression of $\alpha$-defensin 5 and lipocalin 2 and the overproduction of the pro-inflammatory cytokine IL-1B have been closely associated with inflammatory bowel disease $(43,44)$. It was also shown that $\alpha$ defensin may play an important role in the maintenance of intestinal immune homeostasis by controlling the production of IL-1ß (45).

Our study suggests that low aspirin treatment may prevent inflammatory gene expression by maintaining their expression at a level similar to that found in saline rats. Furthermore, the observed down-regulation of inflammatory genes associated with the up-regulation of components of the innate immune system ( $\alpha$-defensin 5 and lipocalin 2 ) in colonic mucosa may favour defence mechanisms against inflammation and may also serve as a surrogate parameter in colon cancer prevention (27). The involvement of these balanced regulatory mechanisms might well explain how long-term administration of aspirin inhibits AOM-induced colonic pre-neoplastic lesions and tumour development.

A tight regulation of epithelial cell proliferation, migration and cell death is critical for the maintenance of colonic mucosal structural and functional integrity. The colon carcinogen AOM may induce an imbalance between proliferation and apoptosis in favour of proliferation through enhanced inflammatory cytokines and MMPs productions. The aspirin-triggered down- regulation of inflammatory genes and up-regulation of hostdefence mediators may favour a rebalanced regulation between proliferation and death of colonic epithelial cells. In this regard, pro-apototic properties of lipocalin 2 and $\alpha$-defensins have been reported $(46,47)$.

Several lines of evidence suggest that the wide range of anti-proliferative potencies of aspirin does not correlate exclusively with its anti-inflammatory effects, since NSAIDs can induce apoptosis in colon cancer cell lines that lack detectable expression of COX-2 protein (48). The balance between cell survival and apoptosis is dependent upon the relative expression of specific genes, such as p53, whose products interact to determine the final outcome of the apoptotic signal. Target genes regulated by p53 include proapoptotic Bax, Fas, DR5, TRAIL and also the anti-apoptotic gene Bcl-2 (49). Indeed, our study showed that AOM initiated an up-regulation of the pro-apoptotic Bax, DR5/ TRAIL and Fas/FasL genes, but also of the anti-apoptotic Bcl-2 gene. Aspirin treatment reduced significantly the high expression level of death receptor genes and their ligands observed in AOM rats. More specifically, we showed that the expression of the anti-apoptotic Bcl-2 gene was dramatically down-regulated, whereas the pro-apoptotic Bax gene remained up-regulated when compared with saline rats and unchanged when compared to AOM rats.

Induction of programmed cell death may result from the activation of two main pathways: the extrinsic apoptotic pathway which is triggered by specific cell surface death receptors: Fas or TRAIL receptors (DR4, DR5), and the intrinsic apoptotic pathway which is induced following mitochondrial injury and is controlled by members of the Bcl-2 family, and more specifically by the anti-apoptotic Bcl-2 protein and the pro-apoptotic Bax protein. The Bcl-2/Bax ratio is a determinant factor for apoptosis and the decline of this ratio favours mitochondria alterations leading to apoptosis (50). Therefore, our present data suggest, that long-term treatment with low dose of aspirin may favour apoptosis through the activation of the intrinsic mitochondrial pathway as supported by the observed decrease of the Bcl-2/Bax transcript ratio when compared with AOM rats.

Our study demonstrates that the long-term (10 months) daily administration of a non-toxic low dose of aspirin after colon cancer initiation by $\mathrm{AOM}$ in rats suppressed tumour formation and reduced by $50 \%$ the formation of pre-neoplastic lesions (ACFs). This is the first study showing that these effects were associated with a 'normalization' in the colonic mucosa of several biomarkers of the inflammatory response such as IL-1ß, TNF $\alpha$, MMP3 and MMP7 gene expression. In addition, aspirin treatment activated the genetic expression of important mediators of the innate immune system such as $\alpha$-defensin 5 (Rd-5) and lipocalin 2 which may favour defence mechanisms against mucosal inflammation (27). A tight regulatory mechanism is involved in the control of cell proliferation and cell death to maintain structural and functional integrity of the colonic mucosa. We demonstrated that AOM perturbated the genetic expression of several mediators involved in the two main apoptotic pathways. Here also aspirin treatment was able to 'normalize' the genetic expression of mediators involved in the control of the extrinsic apoptotic pathway (Fas, FasL, DR5, TRAIL). Interestingly, an important change 
of the Bcl-2/Bax transcript ratio was observed in aspirintreated AOM rats caused by a dramatic and specific downregulation of the anti-apoptotic Bcl-2 transcript. These changes may support an activation of the intrinsic (mitochondrial) apoptotic pathway by aspirin in mucosal cells counteracting the imbalance between cell proliferation and cell death initiated by AOM which favoured the activation of proliferative signals.

In conclusion, the present study identifies new molecular targets triggered by aspirin in the colon and supports the use of non-toxic low dose of aspirin in long-term treatments as a prophylactic approach against colon carcinogenesis. The use of low dose of aspirin single or in association with other chemopreventive agents should be re-assessed in long-term protocols designed for populations (familial predispositions, polypectomized patients, ageing population) at risk to develop the disease.

\section{Acknowledgements}

Souad Bousserouel was supported by a post-doctoral fellowship provided by the Conseil Régional d'Alsace, France. This study was supported by a grant from Conseil Régional d'Alsace and from the Ligue Nationale contre le Cancer, Department du Haut Rhin, France.

\section{References}

1. Lieberman DA: Screening for colorectal cancer. Clin Cornerstone 4: 1-10, 2002.

2. Benamouzig R and Chaussade S: La chimioprevéntion du cancer colorectal. Presse Med 31: 124-128, 2002.

3. Sheehan KM, Sheahan K, O'Donoghue DP, MacSweeney F, Conroy RM, Fitzgerald DJ and Murray FE: The relationship between cyclooxygenase-2; expression and colorectal cancer. JAMA 282: 1254-1257, 1999.

4. Taketo MM: Cyclooxygenase-2 inhibitors in tumorigenesis (part I). J Natl Cancer Inst 90: 1529-1536, 1998.

5. Thun M: Beyond willow bark: aspirin in the prevention of chronic disease. Epidemiology 11: 371-374, 2000.

6. Baron JA: Aspirin and NSAIDS for the prevention of colorectal cancer. Recent Results Cancer Res 181: 223-229, 2009.

7. Ulrich CM, Bigler J and Potter JD: Non-steroidal antiinflammatory drugs for cancer prevention: promise, perils and pharmacogenetics. Nat Rev Cancer 6: 130-140, 2006.

8. Dubé C, Rostom A, Lewin G, Tsertsvadze A, Barrowman N, Code C, Sampson M and Moher D: The use of aspirin for primary prevention of colorectal cancer: a systematic review prepared for the U.S. Preventive Services Task Force. Ann Intern Med 146: 365-375, 2007.

9. Reddy BS, Rao CV, Rivenson A and Kelloff G: Inhibitory effect of aspirin on azoxymethane-induced colon carcinogenesis in F344 rats. Carcinogenesis 14: 1493-1497, 1993.

10. Kapetanovic IM, Bauer KS, Tessier DM, Lindeblad MO, Zakharov AD, Lubet R and Lyubimov A: Comparison of pharmacokinetic and pharmacodynamic profiles of aspirin following oral gavage and diet dosing in rats. Chem Biol Interact 179: 233-239, 2009 .

11. Wargovich MJ, Chen CD, Harris C, Yang E and Velasco M: Inhibition of aberrant crypt growth by non-steroidal antiinflammatory agents and differentiation agents in the rat colon. Int J Cancer 60: 515-519, 1995.

12. Pereira MA, Barnes LH, Rassman VL, Kelloff GV and Steele VE: Use of azoxymethane-induced foci of aberrant crypts in rat colon to identify potential cancer chemopreventive agents. Carcinogenesis 15: 1049-1054, 1994.

13. Craven PA and DeRubertis FR: Effects of aspirin on 1,2-dimethylhydrazine-induced colonic carcinogenesis. Carcinogenesis 13: 541-546, 1992.

14. Craven PA, Thornburg K and DeRubertis FR: Sustained increase in the proliferation of rat colonic mucosa during chronic treatment with aspirin. Gastroenterology 94: 567-575, 1988.
15. Craven PA, Saito R and DeRubertis FR: Role of local prostaglandin synthesis in the modulation of proliferative activity of rat colonic epithelium. J Clin Invest 72: 1365-1375, 1983.

16. DeRubertis FR, Craven PA and Saito R: 16,16-Dimethyl prostaglandin E2 suppresses the increases in the proliferative activity of rat colonic epithelium induced by indomethacin and aspirin. Gastroenterology 89: 1054-1063, 1985.

17. Kuwayama H and Eastwood GL: Effects of water immersion restraint stress and chronic indomethacin ingestion on gastric antral and fundic epithelial proliferation. Gastroenterology 88 : 362-365, 1985.

18. Eastwood GL and Quimby GF: Effect of chronic aspirin ingestion on epithelial proliferation in rat fundus, antrum, and duodenum. Gastroenterology 82: 852-856, 1982.

19. Deschner EE, Long FC, Hakissian M and Herrmann SL: Differential susceptibility of AKR, C57BL/6J, and CF1 mice to 1,2-dimethylhydrazine-induced colonic tumor formation predicted by proliferative characteristics of colonic epithelial cells. J Natl Cancer Inst 70: 279-282, 1983.

20. Deschner EE, Winawer SJ, Katz S, Katzka I and Kahn E: Proliferative defects in ulcerative colitis patients. Cancer Invest 1: 41-47, 1983.

21. Corpet DE and Pierre F: How good are rodent models of carcinogenesis in predicting efficacy in humans? A systematic review and meta-analysis of colon cancer chemoprevention in rats, mice and humans. Eur J Cancer 41: 1911-1922, 2005.

22. Reddy BS: Studies with azoxymethane-rat preclinical model for assessing colon tumor development and chemoprevention. Environ Mol Mutagen 44: 26-35, 2004.

23. Rudolph RE, Domonitz JA, Lampe JW, Levy L, Qu P, Li SS, Lampe PD, Bronner MP and Potter JD: Risk factors for colorectal cancer in relation to number and size of aberrant crypt foci in humans. Cancer Epidemiol Biomarkers Prev 14: 605-608, 2005.

24. Livak KJ and Schmittgen TD: Analysis of relative gene expression data using real-time quantitative PCR and the 2(-Delta Delta C(T)) method. Methods 25: 402-408, 2001.

25. Gunter MJ: Inflammation-related gene polymorphisms and colorectal adenoma. Cancer Epidemiol Biomarkers Prev 15: 1126-1131, 2006.

26. Lu Q, Jiang B, Lin C and Shan T: Dark qberrant crypt foci with activated Wnt pathway are related to tumorigenesis in the colon of AOM-treated rat. J Exp Clin Cancer Res 27: 26, 2008.

27. Ramasundara M, Leach ST, Lemberg DA and Day AS: Defensins and inflammation: the role of defensins in inflammatory bowel disease. J Gastroenterol Hepatol 24: 202-208, 2009.

28. Reddy BS and Rao CV: Chemoprophylaxis of colon cancer. Curr Gastroenterol Rep 7: 389-395, 2005.

29. Jemal A, Tiwari RC, Murray T, Ghafoor A, Samuels A, Ward E, Feuer EJ and Thun MJ: Cancer statistics, 2004. CA Cancer J Clin 54: 8-29, 2004.

30. Macejova D and Brtko J: Chemically induced carcinogenesis: a comparison of 1-methyl-1-nitrosurea, 7,12-dimethyl-benzanthracene, diethyl-nitroso-amine and azoxymethane models. Endocr Regul 35: 53-59, 2001.

31. Takayama T, Katsuki S, Takahashi Y, Ohi M, Nojiri S, Sakamaki S, Kato J, Kogawa K, Miyake H and Niitsu Y: Aberrant crypt foci of the colon as precursors of adenoma and cancer. $\mathrm{N}$ Eng1 J Med 339: 1277-1284, 1998.

32. Molatore S and Ranzani GN: Genetics of colorectal polyps. Tech Coloproctol 8 (Suppl 2): s240-s242, 2004.

33. Gout S and Huot J: Role of cancer microenvironment in metastasis: focus on colon cancer. Cancer Microenviron 1: 69-83, 2008.

34. Ouyang LH and Huang C: Inflammation, a key event in cancer development. Mol Cancer Res 4: 221-233, 2006.

35. Perwez Hussain S and Harris CC: Inflammation and cancer: an ancient link with novel potentials. Int J Cancer 121: 2373-2380, 2007.

36. Raul F, Gossé F, Osswald AB, Bouhadjar M, FoltzerJourdainne C, Marescaux J and Soler L: Follow-up of tumor development in the colons of living rats and implications for chemoprevention trials: assessment of aspirin-difluoromethylornithine combination. Int J Oncol 31: 89-95, 2007.

37. Gupta RA and Dubois RN: Colorectal cancer prevention and treatment by inhibition of cyclooxygenase-2. Nat Rev Cancer 1: $11-21,2001$.

38. Marnett LJ and DuBois RN: COX-2: a target for colon cancer prevention. Annu Rev Pharmacol Toxicol 42: 55-80, 2002. 
39. Zucker S and Vacirca J: Role of matrix metalloproteinases (MMPs) in colorectal cancer. Cancer Metastasis Rev 23: 101-107, 2004.

40. Goetz DH, Holmes MA, Borregaard N, Bluhm ME, Raymond KN and Strong RK: The neutrophil lipocalin NGAL is a bacteriostatic agent that interferes with siderophore-mediated iron acquisition. Mol Cell 10: 1033-1043, 2002.

41. Papo N and Shai Y: Host defense peptides as new weapons in cancer treatment. Cell Mol Life Sci 62: 784-790, 2005.

42. Lee HJ, Lee EK, Lee KJ, Hong SW, Yoon Y and Kim JS: Ectopic expression of neutrophil gelatinase-associated lipocalin suppresses the invasion and liver metastasis of colon cancer cells. Int J Cancer 118: 2490-2497, 2006.

43. Simms LA, Doecke JD, Walsh MD, Huang N, Fowler EV and Radford-Smith GL: Reduced alpha-defensin expression is associated with inflammation and not NOD2 mutation status in ileal Crohn's disease. Gut 57: 903-910, 2008.

44. Friedl A, Stoesz SP, Buckley P and Gould MN: Neutrophi gelatinase-associated lipocalin in normal and neoplastic human tissues. Cell type-specific pattern of expression. Histochem J 31: 433-441, 1999.
45. Shi J, Aono S, Lu W, Ouellette AJ, Hu X, Ji Y, Wang L, Lenz S, van Ginkel FW, Liles M, Dykstra C, Morrison EE and Elson CO: A novel role for defensins in intestinal homeostasis: regulation of IL-1beta secretion. J Immunol 179: 1245-1253, 2007.

46. Devireddy LR, Teodoro JG, Richard FA and Green MR: Induction of apoptosis by a secreted lipocalin that is transcriptionally regulated by IL-3 deprivation. Science 293: 829-834, 2001.

47. Aarbiou J, Tjabringa GS, Verhoosel RM, Ninaber DK, White SR Peltenburg LT, Rabe KF and Hiemstra PS: Mechanisms of cell death induced by the neutrophil antimicrobial peptides alphadefensins and LL-37. Inflamm Res 55: 119-127, 2006.

48. Lai MY, Huang JA, Liang ZH, Jiang HX and Tang GD Mechanisms underlying aspirin-mediated growth inhibition and apoptosis induction of cyclooxygenase- 2 negative colon cancer cell line SW480. World J Gastroenterol 14: 4227-4233, 2008.

49. Fridman JS and Lowe SW: Control of apoptosis by p53. Oncogene 22: 9030-9040, 2003

50. Buckley AR: Lessons from anticancer research might provide new insights into mechanisms of hormone action. Trends Endocrinol Metab 12: 87-89, 2001 